\title{
THE EFFECT OF SEVERAL VARIABLES ON THE SPECIFIC GRAVITY OF SECOND-GROWTH DOUGLAS FIR ${ }^{1}$
}

\section{BY R. W. WELLWOOD2}

\section{SUMMARY}

Second-growth stands of mixed Douglas fir and western hemlock produce wood that varies considerably in quality, expressed as specific gravity, depending upon the factors of position in the stem, crown class and site index. Data were obtained from sample Douglas fir trees removed in a thinning operation on the University Research Forest, Haney, British Columbia. Samples represent three levels in the stem (stump, one-third total height and merchantable top), three major crown classes (Dominant, Codominant and Intermediate) and site indices from 93 to 160.

It was determined that wood at the base of the tree was more dense than at the higher levels, although this difference failed to show significance for the better sites. Considering the differences, at the same levels, between trees of the three crown classes, Dominants had significantly lower values of specific gravity than either the Codominants or the Intermediates. No significant differences occurred between the latter two classes. When the variable of site is tested, it is found that the "Good" sites have significantly lower specific gravities than do the "Average" sites, for comparable sections. The interaction between site and crown class reveals that the differences above hold for the mean of all sites, and for "Average" sites, but that on "Good" sites no significant difference exists between any of the crown classes.

In managing second-growth stands of this nature the forester should keep in mind the variation in specific gravity that will occur. He can regulate rate of growth of individual trees and of stands, within limits, so as to produce wood of the desired quality.

INTRODUCTION

The management of second-growth coniferous stands calls for an intelligent appraisal of the factors involved in producing the types of wood of greatest economic value. This is true in particular for the mixed stands of Douglas fir and western hemlock in the Pacific Northwest, where multiple uses are becoming available for each species. Wood from these stands is used in two common conditions: (a) in natural form, as produced in the tree, often modified in size by sawing; or (b), reduced by chemical and/or mechanical means to a defibered state. In either condition the quality of the wood must be judged by some criterion. Since solid wood is most frequently used because of its strength properties, these would seem to be the most logical criteria of quality. Wood for

1 Research Paper No. 2, Faculty of Forestry, University of British Columbia, Vancouver, B.C

2 Professor, Faculty of Forestry, University of British Columbia. vided funds with which to initiate this research work. Further funds were provided by re-
search grants from the University of British Columbia. H. G. Bancroft, D. A. Girard and B. P. Page, senior students in Forestry, did valuable work as student assistants. 
pulping is judged in quality by the strength properties of the resulting pulp or paper, and by the yield of pulp per unit of wood volume.

Strength in wood is governed by a number of factors including freedom from decay, straightness of grain, placement of knots, and the presence or absence of other strength-reducing defects or irregularities. By and large, however, considering only clear wood, strength is in direct proportion to the density or specific gravity of that wood. Specific gravity can therefore be used directly as an indication of wood quality.

It has been known for some time that specific gravity in many species is affected by the rate of growth of the tree. For the conifers in general, the faster the growth rate the lower the resultant specific gravity of the wood. There is a direct relationship between the width of the growth ring and the proportion of spring wood and summer wood components of that ring. In comparing trees of widely differing growth rates, obviously the tree which has the faster growth rate would produce a proportionately greater amount of spring wood conductive tissue, whereas the tree of more moderate growth rate would produce a more even balance between conductive and supporting (mechanical) tissue.

The silviculturist, in managing second-growth stands, is able to regulate rate of growth, and thereby specific gravity, by means of tree spacing, thinnings and other cultural measures. He has long realized that an open stand produces limby trees, undesirable because of the knot size and distribution, excessive taper and poor form. Excluding the factors above, too much emphasis has been placed on accelerated volume growth and too little on the characteristics of the resultant wood. Numerous publications relating to the statements above have been issued by the staff of the United States Forest Products Laboratory, in particular those by Paul. (9)

\section{DATA}

An experiment (2) has been set up recently at the University Research Forest, Haney, British Columbia, to test the effect of thinning in second-growth stands of mixed Douglas fir and western hemlock. As a part of this study, sample discs were taken from log ends from representative trees removed in the thinning operation. These discs were selected to provide an analysis of the specific gravity at three levels in each tree, namely (a) stump height, (b) one-third total height and (c) the top of the merchantable stem. Individual trees within the plots represent the three major crown classes, Dominant, Codominant and Intermediate. A few suppressed trees were included in the samples taken, but are not considered in statistical comparisons. Plots were established on sites whose site indices range from 93 to 160 , and ages from 59 to 78 years. In all some 133 Douglas fir and 40 western hemlock trees were sampled. This paper considers only the Douglas fir.

Since the experiment was primarily a thinning operation, with commercial recovery made of the thinnings wherever feasible, the position of the disc in the section at one-third total height varies according to the proximity 
of the nearest 16-foot log end. It was found that this position also approximated one-half the merchantable stem length, consequently the section is called the "Middle" section. Stump height was constant at 1.5 feet, whereas the top was usually taken as 5 inches d.i.b., the present merchantable limit for pulpwood in this area.

After cutting, the sample discs were coated with paraffin to restrict end checking. For each disc the average radius was determined and a segment of the disc removed, one cut being made along the average radius. Specific gravities were determined by the standard immersin method. Other data collected include decadal growth and decadal percentage of summerwood.

\section{RESULTS}

Specific gravity determinations are summarized in Table 1. Individual sample plots are included in the groupings of "Average Sites" or "Good Sites". The division is purely arbitrary, representing conditions in the University Research Forest, rather than over any wide region. In Table 2 data are further segregated by crown classes, thereby giving a broader comparison. Statistical tests of the differences between mean values (4) appear in Table 3.

When results are summarized according to position in the stem (Table 1), the decrease in specific gravity with increased height in the tree becomes apparent. This difference is highly significant (Table 3(i)) when data from all trees are tested. Table 3 (ii) and (iii) indicate, however, that this difference is significant for the "Average" sites but not for the "Good" sites. Although a consistent difference exists for the latter group it could be due to chance.

Further study of Table 1 shows higher mean specific gravities, at comparable sections, for the "Average" sites than for the "Good" sites. Table 3

TABLE 1

Summary of Mean Specific Gravities for Sample Douglas Fir Trees from University Research Forest, Haney, British Columbia.

\begin{tabular}{|c|c|c|c|c|c|c|c|}
\hline \multirow[b]{2}{*}{ Group } & \multicolumn{3}{|c|}{ Sample Plot } & & \multicolumn{3}{|c|}{ Mean Specific } \\
\hline & & & Total & Number & & Gravity* & \\
\hline \multirow[t]{2}{*}{$\begin{array}{l}\text { Classifif } \\
\text { cation }\end{array}$} & $\begin{array}{l}\text { Num- } \\
\text { ber } \\
106\end{array}$ & $\begin{array}{l}\text { Site } \\
\text { Index } \\
03\end{array}$ & $\begin{array}{l}\text { Age } \\
\text { Years }\end{array}$ & $\begin{array}{l}\text { of } \\
\text { Samples }\end{array}$ & $\begin{array}{l}\text { Top } \\
0496\end{array}$ & $\begin{array}{l}\text { Section } \\
\text { Mid. } \\
0.547\end{array}$ & $\begin{array}{l}\text { Base } \\
0.559\end{array}$ \\
\hline & 102 & 100 & 73 & 27 & 0.526 & 0.559 & 0.590 \\
\hline \multirow[t]{3}{*}{ Average } & 104 & 110 & 60 & 19 & 0.500 & 0.5 & 0.542 \\
\hline & 105 & 110 & 60 & 2 & 0.520 & & 0.566 \\
\hline & 109 & 115 & 59 & 22 & 0.490 & 0. & 0.526 \\
\hline \multicolumn{3}{|c|}{ Mean of Group } & & 111 & 0.5082 & 0.5380 & 0.5585 \\
\hline & 101 & 140 & 78 & 16 & 0.487 & 0.492 & 0.496 \\
\hline Good & 108 & 160 & 59 & 6 & 0.457 & 0.474 & 0.509 \\
\hline \multirow[t]{2}{*}{ All } & $\operatorname{an}$ of & oup & & 22 & 0.4786 & 0.4873 & 0.4995 \\
\hline & $\tan 0$ & & & 133 & 0.5033 & 0.5296 & 0.5487 \\
\hline
\end{tabular}

*based on oven-dry weight and volume. 


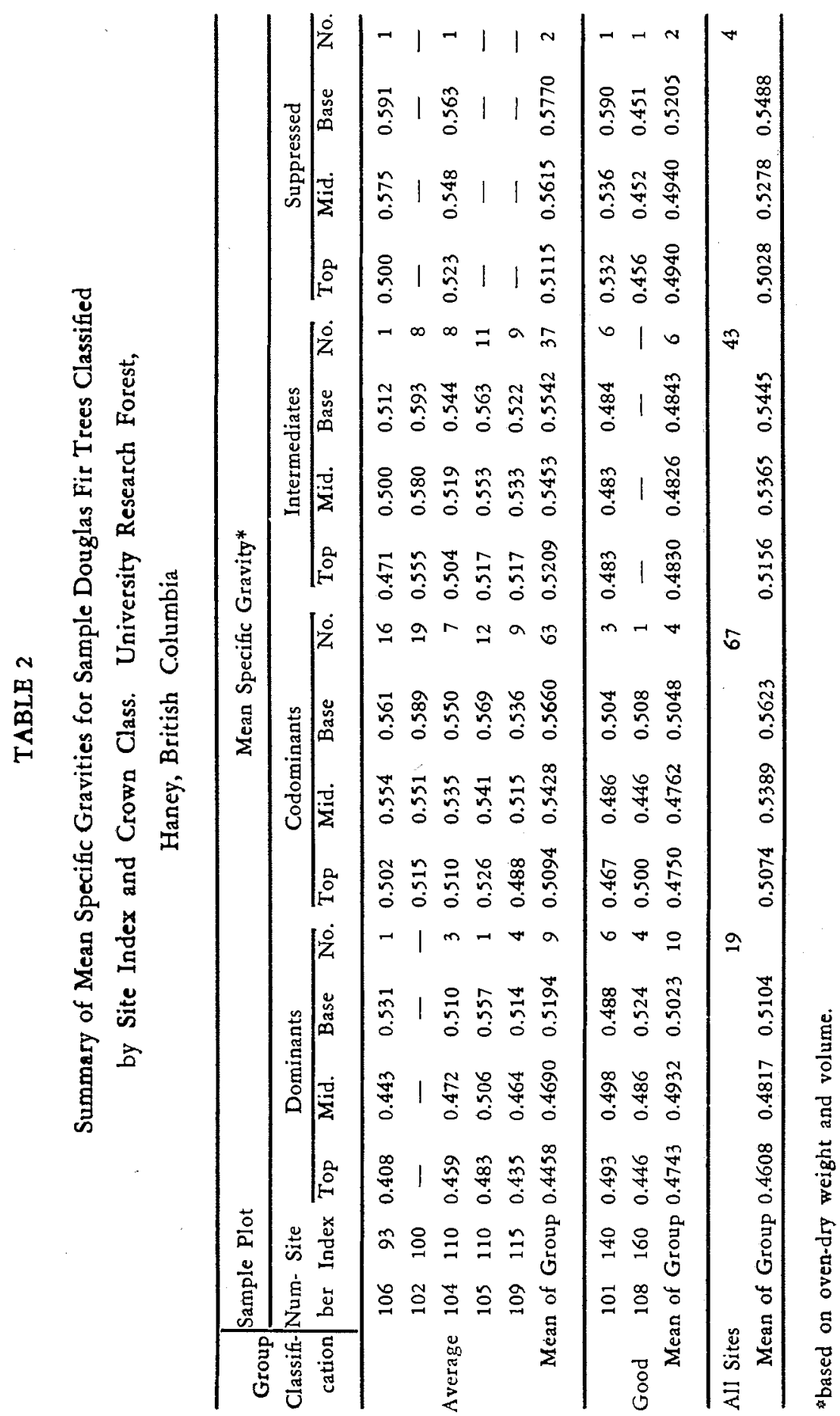


TABLE 3

Tests of Significance of Difference Between Mean Specific Gravities for Sample Douglas Fir Trees from University Reasearch Forest, Haney, British Columbia.

(i) Description of Test

Difference Between
Means

Standard

Error of
Difference

Value

Desrees

Means

0.00644

(a) Top vs Middle Section

0.0264

0.0455

0.00624

0.00643

7.284

(b) Top vs Basal

0.0191

2.971

(ii)

All Trees, Average Sites

(a) Top vs Middle Section

(b) Top vs Basal

0.0298

0.0503

0.00705

0.00696

4.237

(c) Middle vs Basal " 0.0205

0.00664

7.234

(iii)

All Trees, Good Sites

(a) Top vs Middle Section 0.0087

(b) Top vs Basal " 0.0209

0.0209

0.01381

0.01489

0.01286

0.630

(c) Middle vs Basal

0.0122

(iv)

All Trees,

Average vs Good Sites

(a) Top Sections

(b) Middle "

0.0296

0.0507

0.01216

0.00961

2.430

(c) Basal

0.0590

0.01083

5.447

131

131

131

(v)

All Sites, Dom. vs

Codom. Crown Class

(a) Top Sections

(b) Middle ".

(c) Basal

0.0466

0.0572

0.0519

0.01213

0.01088

0.00968

3.842

5.257

5.362

$\begin{array}{ll}84 & * * \\ 84 & * * \\ 84 & * *\end{array}$

(vi)

All Sites, Dom. vs

Intermed. Crown Class

(a) Top Sections

(b) Middle "

0.5486

0.5483

0.01392

0.01324

3.942

(c) Basal

0.3407

0.01224

4.142

(vii)

All Sites, Codom. vs

Intermed. Crown Class

(b) Middle

(c) Basal

0.01022

0.780

0.216

1.742

(viii)

Average Sites,

Dom. vs Codom. Crown Class

(a) Top Sections

(b) Middle ""

0.0637

(c) Basal

0.0738

0.01586

0.01053

4.015

0.01142

7.014

*Significant at 5 per cent level

**Significant at 1 per cent level 
(ix)

Description of Test

Average Sites,

Dom. vs Intermed.

Crown Class

(a) Top Sections

(b) Middle ""

(c) Basal

(x)

Average Sites,

Codom. vs Intermed.

Crown Class

(a) Top Section

(b) Middle "

(c) Basal

(xi)

Good Sites,

Dom. vs Codom.

Crown Class

(a) Top Sections

(b) Middle "

(c) Basal

(xii)

Good Sites,

Dom. vs Intermed.

Crown Class

(a) Top Sections

(b) Middle ":

(c) Basal

(xiii)

Good Sites,

Codom. vs Intermed.

Crown Class

(a) Top Sections

(b) Middle "

(c) Basal

(xiv)

Dom. Crown Class,

Average vs Good Sites

(a) Top Sections

(b) Middle"

(c) Basal

(xv)

Codom. Crown Class,

Average vs Good Sites

(a) Top Section

(b) Middle "

(c) Basal

(xvi)

Intermed. Crown Class

Average vs Good Sites

(a) Top Sections

(b) Middle "

(c) Basal

Difference

Between

Heans

Standard

Error of

Valne

Degrees

Freedom Remarks

0.0752

0.0763

0.0348

0.01714

0.01350

0.01384

4.386

5.649

2.514

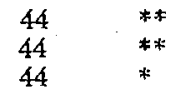

0.0115

0.0025

0.0118

0.01065

0.01143

0.01041

1.079

0.219

1.131

98

98

98

-

0.0007

0.0170

0.0025

0.01854

0.02041

0.01544

0.038

0.833

0.162

12

12

12

0.0379

0.0626

0.0344

0.0666

0.0612

0.0126

0.01443

0.00997

2.714

4.612

6.138

0.574

0.904

0.571

0.392

1.164

$\begin{array}{ll}8 & - \\ 8 & -\end{array}$

**Significant at 1 per cent level
0.01225

0.01406

3.093

3.860

$\begin{array}{ll}65 & \neq \\ 65 & * \\ 65 & *\end{array}$

$\begin{array}{ll}41 & \neq \\ 41 & \neq \\ 41 & \neq\end{array}$


(iv) indicates that the difference is significant for the three sections. In the case of the basal section the mean specific gravity is 12 per cent lower on "Good" sites than it is on "Average" sites. A graph of mean plot specific gravity over site index, not included herein, indicates a straight line relationship between the variables, with a decreasing value of specific gravity for increasing values of site index. The restricted number of the higher site indices sampled limits the dependability of the curves so that trends, rather than absolute values, are indicated.

Table 2 presents the mean values by plots and groups of plots, for the crown classes. Differences again are apparent, many of them being significant, as shown in Table $3(\mathrm{v})$ to (xvi) inclusive. This condition holds when comparing Dominants with Codominants and with Intermediates, for all sites together and for "Average" sites (Table 3 (v), (vi), (viii) and (ix)). No significant difference exists between Codominants and Intermediates for the above two site groups (Table 3 (vii) and (x)), nor between any of the crown classes for the "Good" sites (Table 3 (xi), (xii) and (xiii)). In comparing differences between site groups, within the same crown class, and for the same section (Table 3 (xiv), (xv) and (xvi)), it is seen that no significant difference exists within the Dominant crown class, but that differences within both the Codominant and Intermediate crown classes are highly significant.

\section{Position}

\section{DISCUSSION}

It is a generally accepted fact that the specific gravity of wood near the centre of coniferous trees will be low. Specific gravity will generally increase with distance from the pith (synonymous with increasing age), at the same level in the tree, to some maximum value. For this reason the specific gravity of the older basal section will tend to exceed that of the younger middle and top sections, as shown in Tables 1 and 2. (Although the total age of plot number 101 was higher than that of the others, the effect of age on specific gravity was not considered.) Examination of basic data shows that although the mean specific gravity of the basal sections exceeds that of the top sections for the grouped data, in about 20 per cent of the individual trees the reverse condition holds. This lack of consistency is in accord with the findings of other writers, as noted by Brown, Panshin and Forsaith. (3) It should be noted that on the "Good" sites, although the difference in specific gravity between top and lower sections is not significant statistically (Table 3 (iii)), a positive trend is indicated in Table 1.

In practice the top $\log$ of the tree is of low economic value. With close utilization in the woods it may be diverted to the pulp mill rather than the sawmill. Here, its lower specific gravity, plus the presence of numerous knots, will result in a pulp yield well below that of the average for the species.

\section{Crown Class}

The fact that the Dominants produce wood of the least specific gravity tested is not unexpected. These trees have the largest crowns and the most 
vigorous growth, hence would have the greatest amount of conductive (springwood) tissue in the annual rings. A property not always considered is the large deviation of the fibril angle occurring in the cell walls of the springwood tracheids. The adverse effect of this characteristic on strength and longitudinal shrinkage, accentuated in fast-growing wood, is noted by several writers $(6,10)$. Silvicultural treatments favoring the Dominants would not produce trees with wood of the highest quality. Provided growth is not too rapid, these trees should provide much useful material, including peeler stock which, of necessity, must be of large size. (Face grade veneer will not necessarily result because the $\log$ is large-sized, however. (5))

The slower growth of the Codominants will provide the best structural timber. Individually these trees will not be as large as the Dominants, but in number and total volume they form a substantial portion of the stand.

The Intermediate trees, while having a high specific gravity, are smaller than average in size, and will not form as important a part of the final stand as the two higher crown classes. A large portion of the stand mortality will take place in this crown class. Much of this material could be recovered in the form of thinnings, to make excellent pulping material (7), its high specific gravity resulting in a high pulp yield.

3. Site

The better sites will produce the greatest annual increment of wood, but of appreciably lower specific gravity than wood from poorer site values. As noted above, in the trees tested this difference can be as much as 12 percent. It was also noted that no significant difference exists for specific gravity between crown classes on these sites. For this reason it would appear that they should be managed to produce the maximum amount of wood possible, consistent with long clear boles and freedom from openings in the stand that would result in long crowns, windfall and breakage, and compression wood defects. Alexander (1) states that the maximum rate of growth for Douglas fir should be six rings per inch of radius if we are to produce timber "which will possess adequate mechanical strength for the most exacting heavy construction, together with high specific gravity for high pulp yield per unit of measurement." This maximum rate of growth would not produce the most desirable peeler stock.

The poorer sites are not those that a forester would select by preference. They will never yield a high volume per acre even on a long rotation, nor will they produce large individual trees. They will produce trees with a higher than average specific gravity, and with small, tight knots (8), thus giving a high pulp yield on the one hand, or on the other, wood of good strength properties particularly suited for lumber of small dimensions for laminating purposes.

The average sites of the region will produce wood of good strength properties, lending themselves to silvicultural treatment for the production of high quality wood. 


\section{REFERENCES CITED}

1. ALEXANDER, J. B. 1950. The physical and mechancial properties of second-growth

2. ALLEN, GEORGE $S$. Bulletin No. 169. Forest Research at the University of British Columbia, Faculty of Forestry. University of British Columbia, Research Note No. 1.

3. BROWN, H. P., A. J. PANSHIN and C. C. FORSAITH. 1949. Textbook of Wood Technology. Volume 1. First edition; p. 652. McGraw-Hill Book Company, Inc., New York

4. FISHER, R. A. 1950. Statistical methods for research workers. Eleventh edition; p. 354 Hafner Publishing Company, New York.

5. FLEISCHER. H. O. 1949. Suitability of second-growth Douglas-fir logs for veneer. Jour. of Forestry $47: 533-537$.

6. KOEHLER, ARTHUR. 1946. Longitudinal shrinkage of wood. For. Prod. Lab. Report No. R1093.

7. PAUL, BENSON H. 1947. Thinnings from second-growth Douglas-fir for pulp. For.

Prod. Lab. Report No. Ri 1689 .

8. Prod. Lab. 1947. Knots in second-growth Douglas-fir. For. Prod. Lab. Report.

9. No. R1690 1950 . Quality of second-growth Douglas-fir and suggested means of improvement. For. Prod. Research Soc. Proc. 4 : 16-23.

10: PILLOW, M. Y. and R. F. LUXFORD, 1937. Structare, aceurrence, and propertiea of compression wood. U.S.D.A. Tech. Bull. No. 646. 


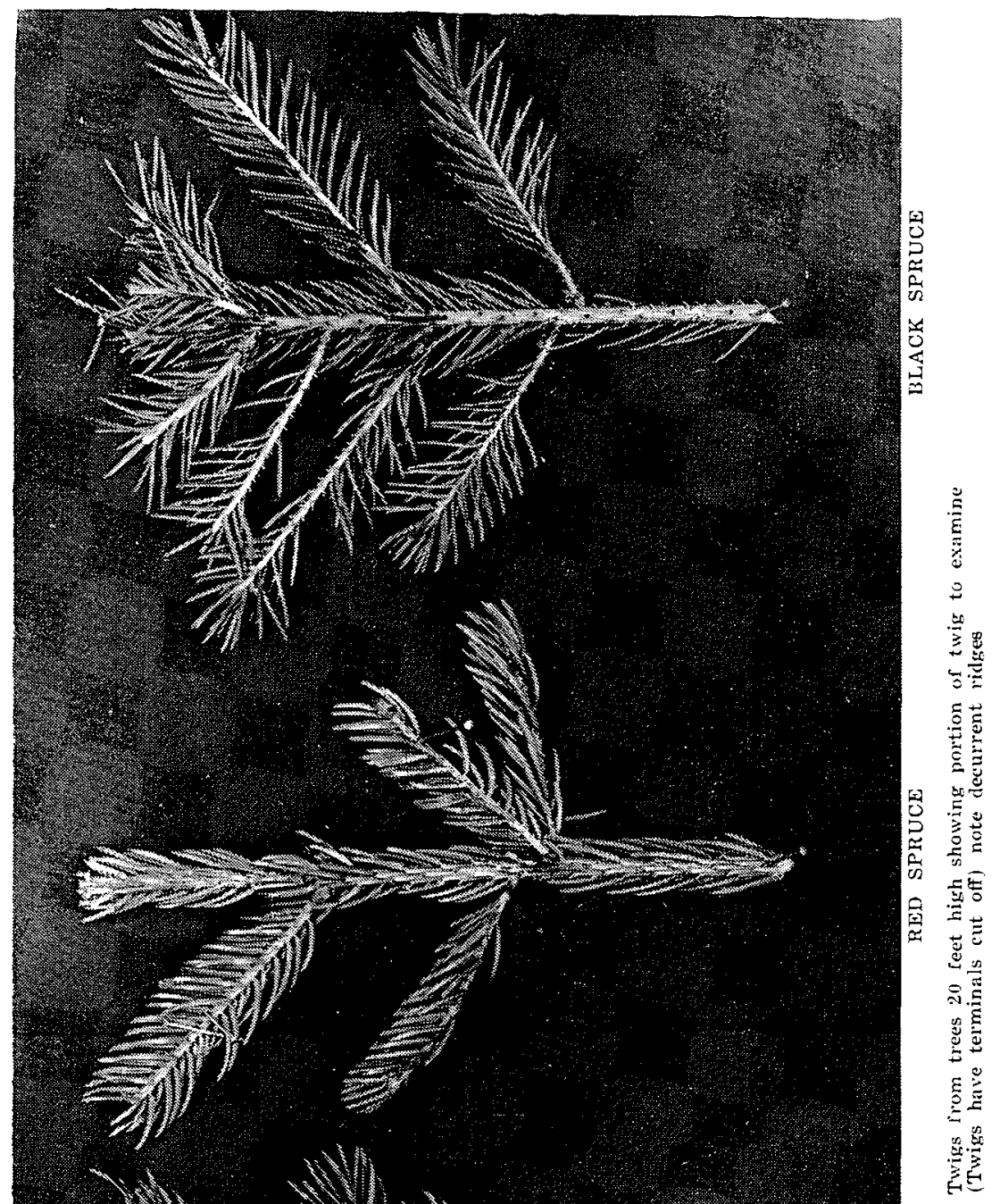




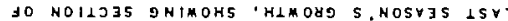

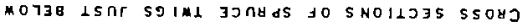

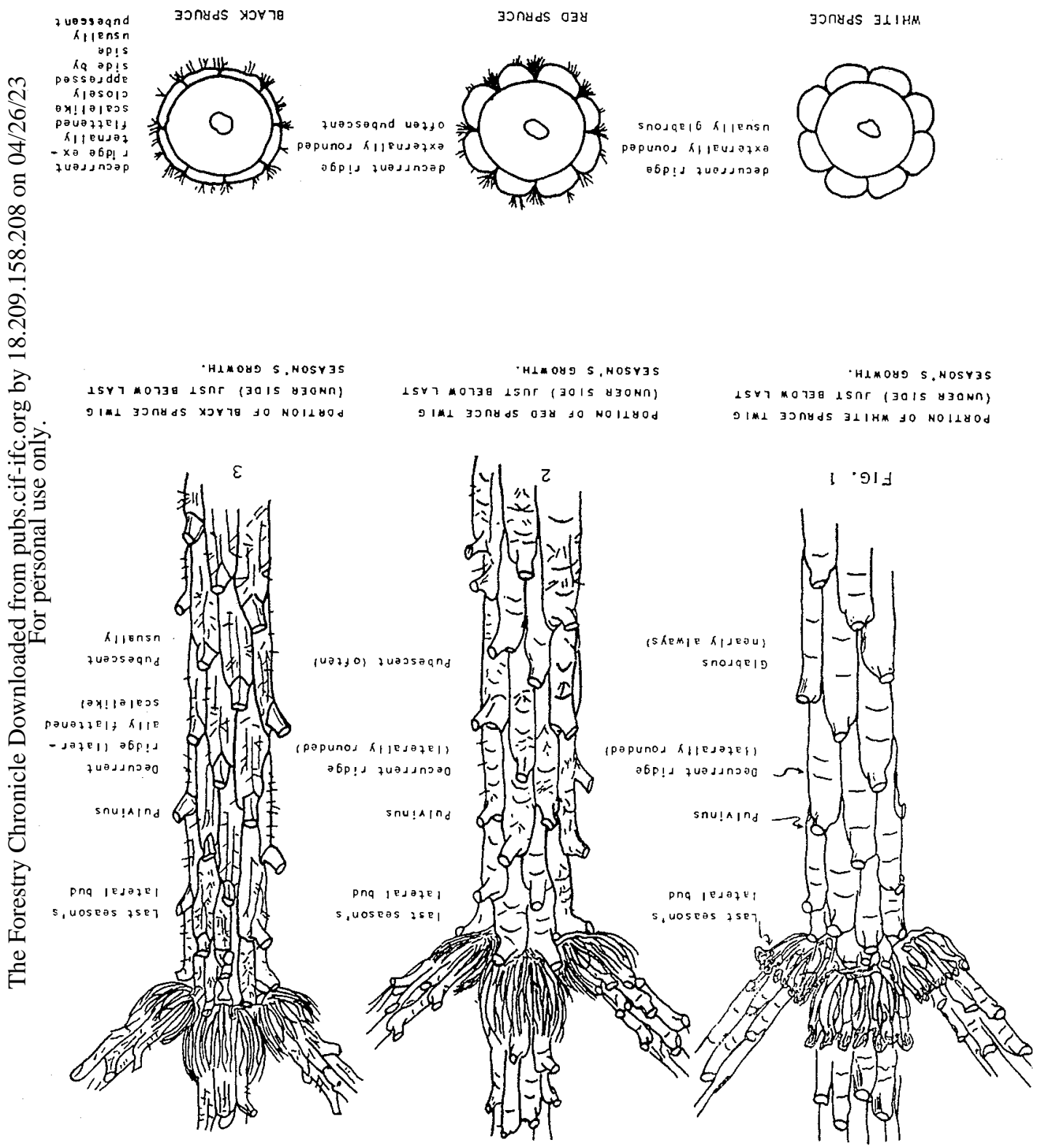

